\title{
Accuracy assessment of global internal tide models using satellite altimetry
}

Loren Carrere ${ }^{1}$, Brian K. Arbic ${ }^{2}$, Brian Dushaw ${ }^{3}$, Gary Egbert ${ }^{4}$, Svetlana Erofeeva ${ }^{4}$, Florent Lyard ${ }^{5}$, Richard D. Ray ${ }^{6}$, Clément Ubelmann ${ }^{7}$, Edward Zaron ${ }^{8}$, Zhongxiang Zhao ${ }^{9}$, Jay F. Shriver ${ }^{10}$, Maarten 5 Cornelis Buijsman ${ }^{11}$, Nicolas Picot ${ }^{12}$

${ }^{1}$ CLS, Ramonville-Saint-Agne, 31450, France

${ }^{2}$ University of Michigan, Ann Arbor, MI, USA

${ }^{3}$ no affiliation, Girona, 17004, Spain

$10{ }^{4}$ Department Geology and Geophysics, Oregon State University, Corvallis, OR 97331-5503, USA

${ }^{5}$ LEGOS-OMP laboratory, Toulouse, 31401, France

${ }^{6}$ NASA Goddard Space Flight Center, Greenbelt, MD 20771, USA

${ }^{7}$ Ocean Next, La Terrasse, 38660, France

${ }^{8}$ Department of Civil and Environmental Engineering, Portland State University, Portland, OR 97207-0751, USA

$15{ }^{9}$ Applied Physics Laboratory, University of Washington, Seattle, WA, USA

${ }^{10}$ Naval Research Laboratory, Stennis Space Center, MS, USA

${ }^{11}$ Division of Marine Science, University of Southern Mississippi, Stennis Space Center, MS 39529, USA

${ }^{12} \mathrm{CNES}$, Toulouse, 31400 , France

20 Correspondence to: L. Carrere (1carrere@groupcls.com)

\section{Supplementary materials}

The plots of the amplitude of the M2 internal tide on the IT regions defined in Figure 1 are provided below. 

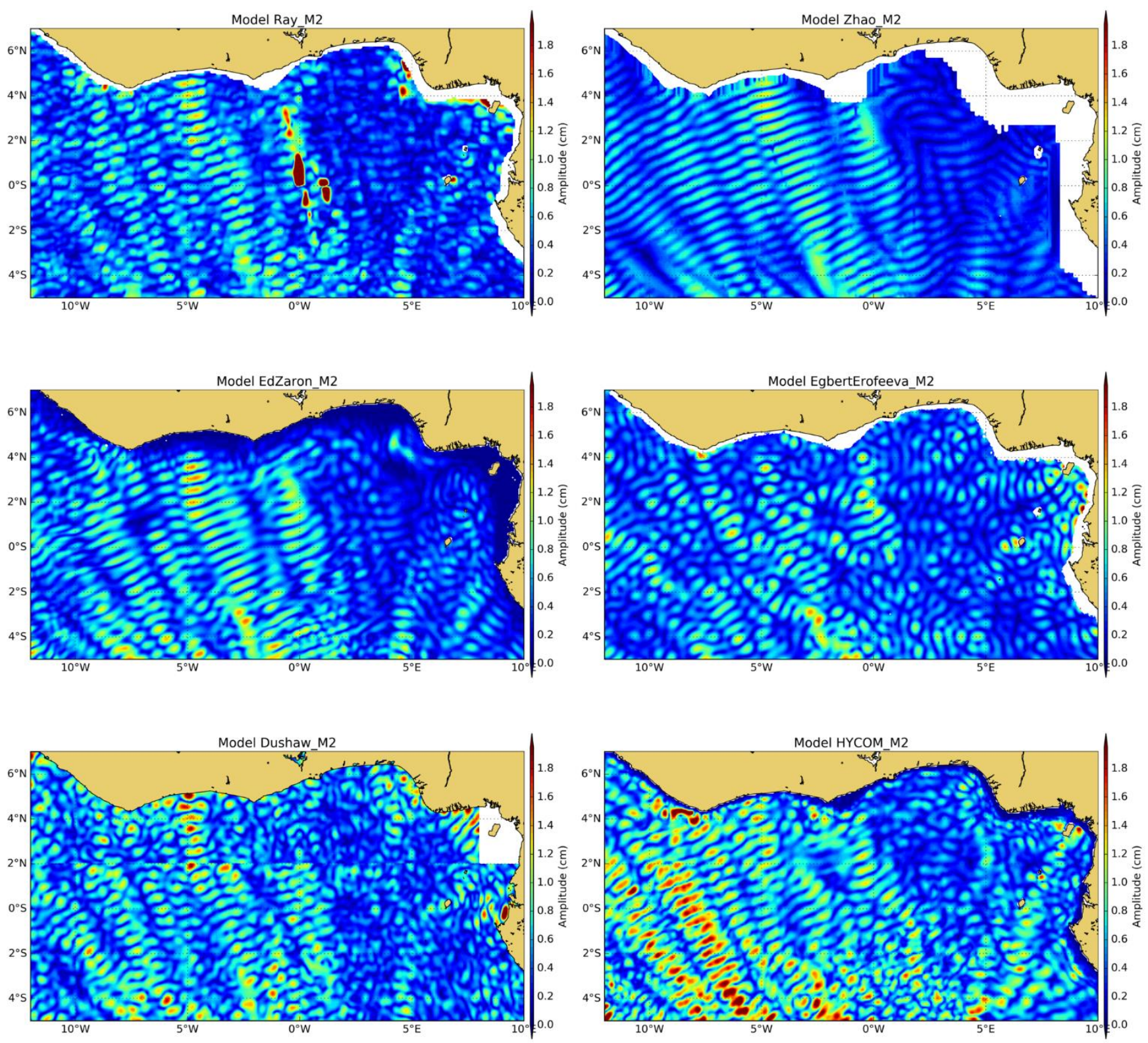

Figure S1: amplitude of the IT models for M2 tide component on Gulf Of Guinea region 

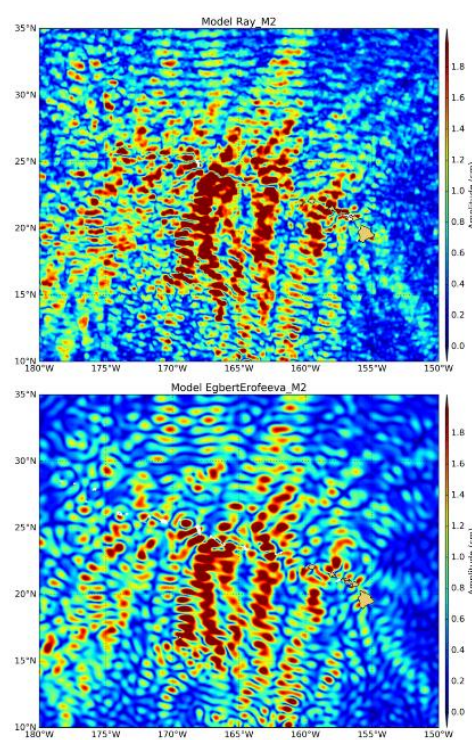
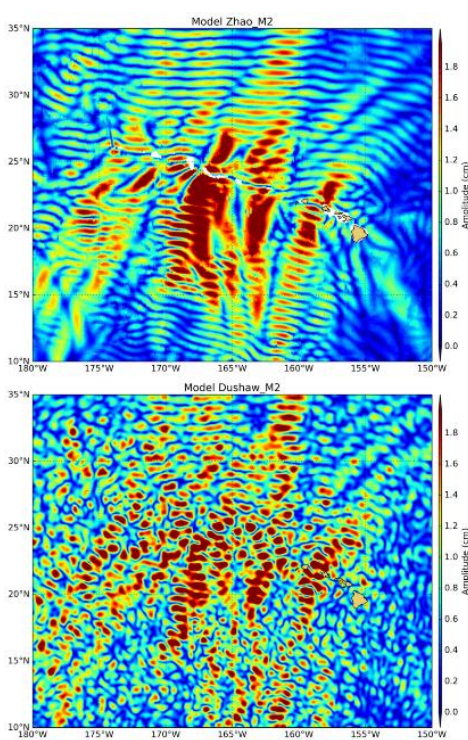
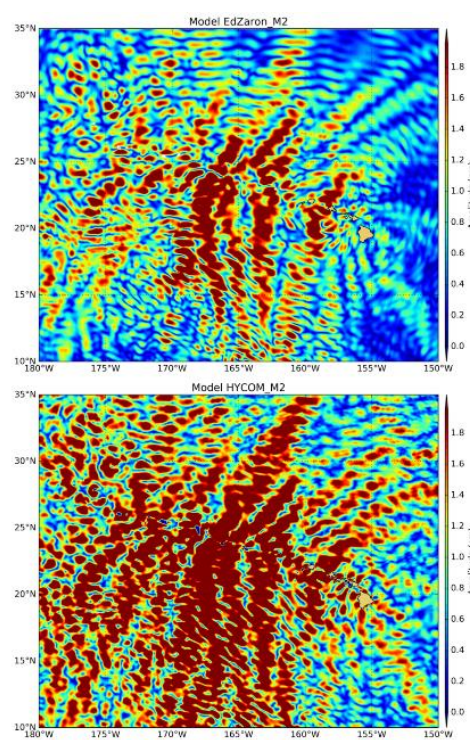

Figure S2: amplitude of the IT models for M2 tide component on Hawaii region 

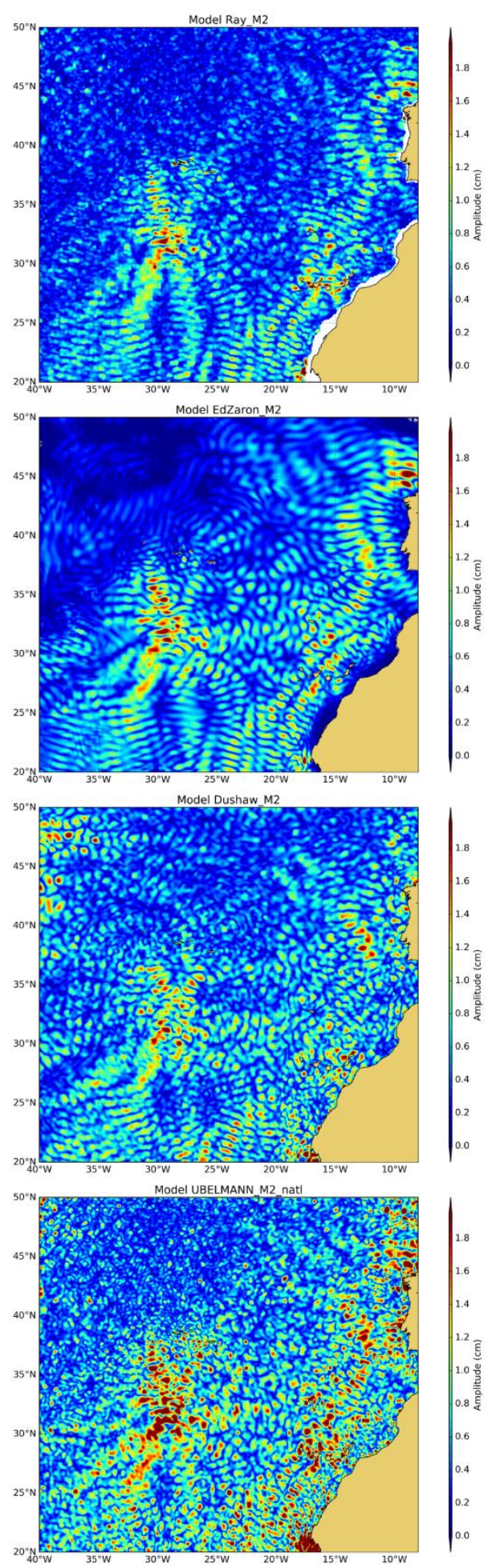
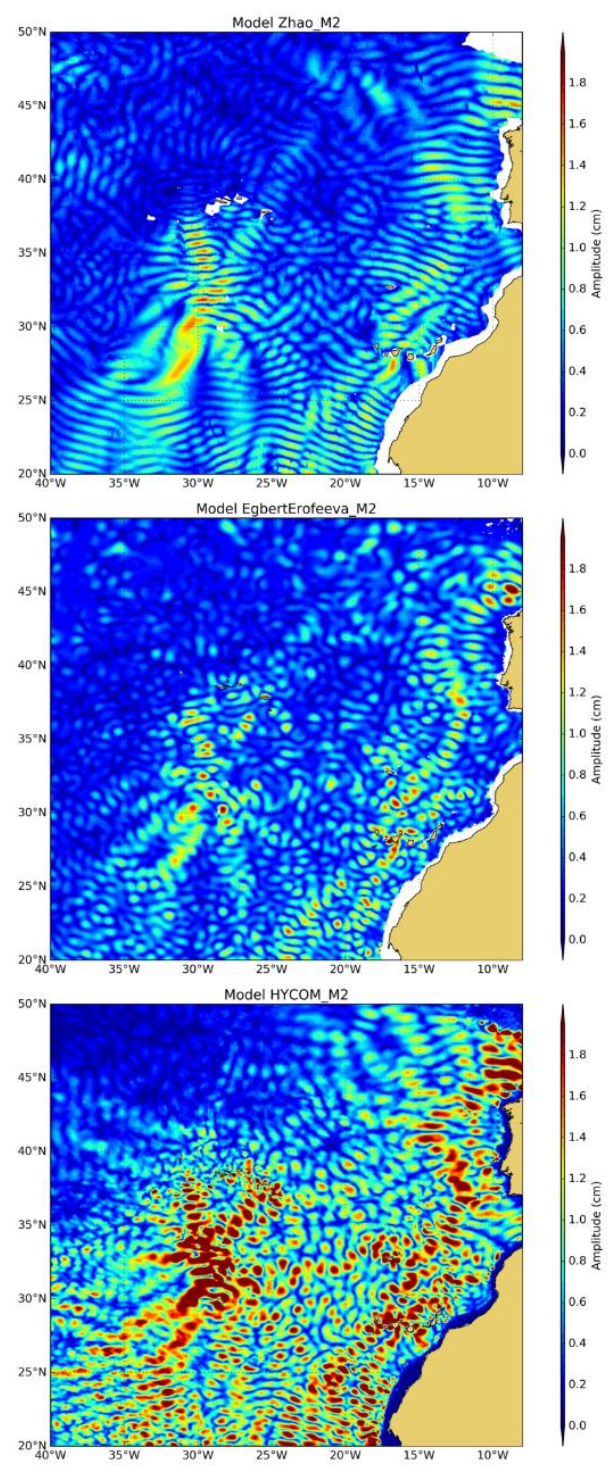

Figure S3: amplitude of the IT models for M2 tide component on NPAC region 

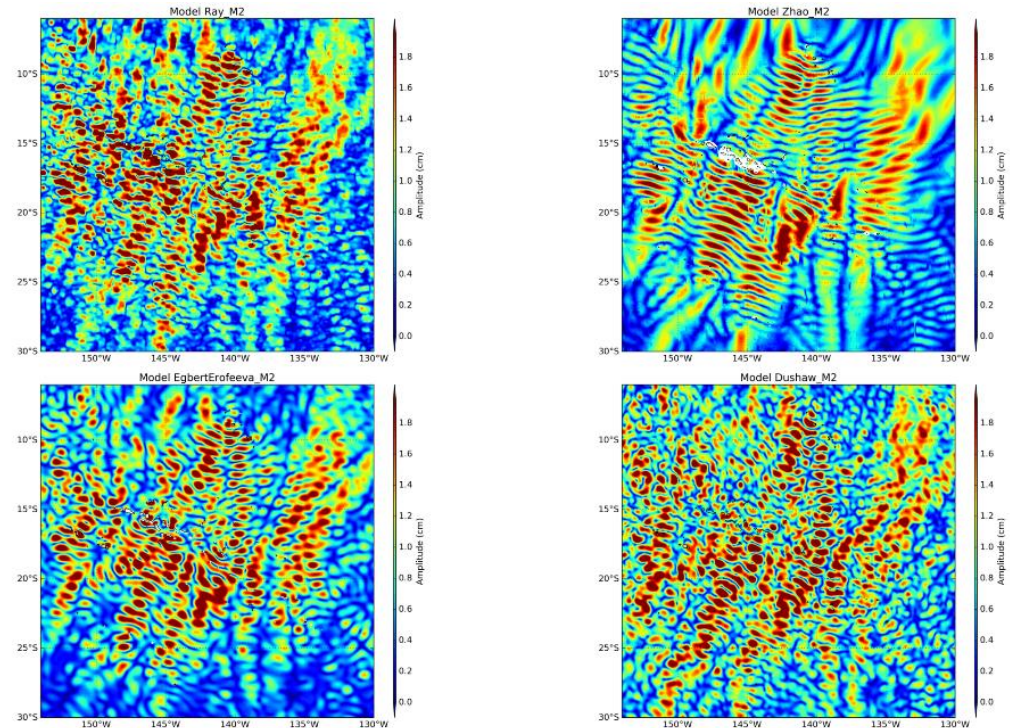

Figure S4: amplitude of the IT models for M2 tide component on Tahiti region
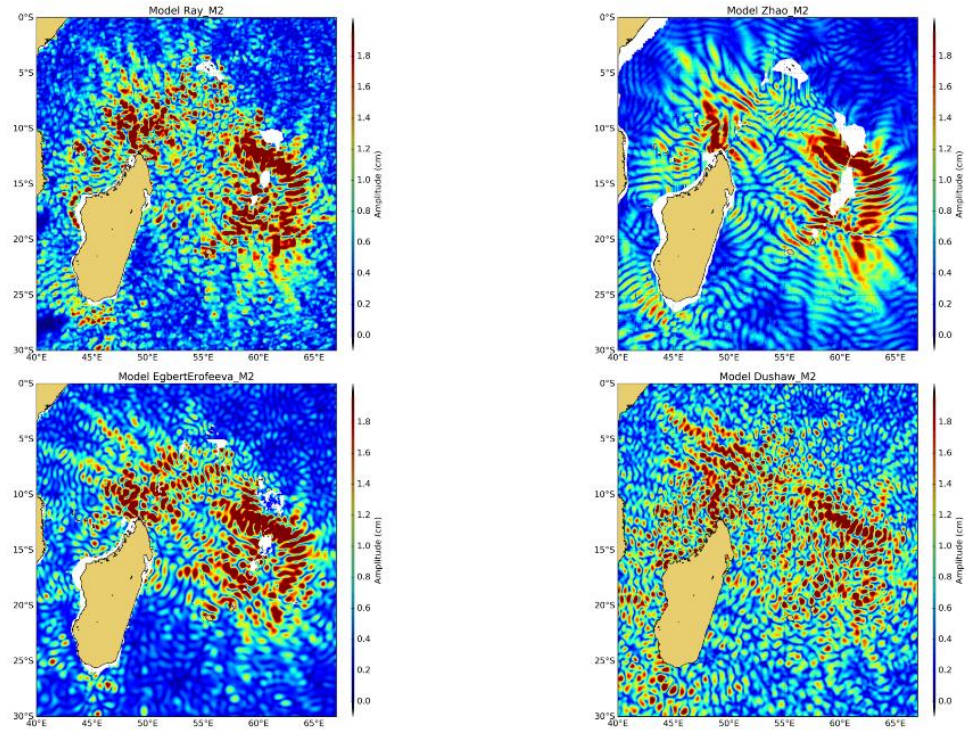

Figure S5: amplitude of the IT models for M2 tide component on Madagascar region
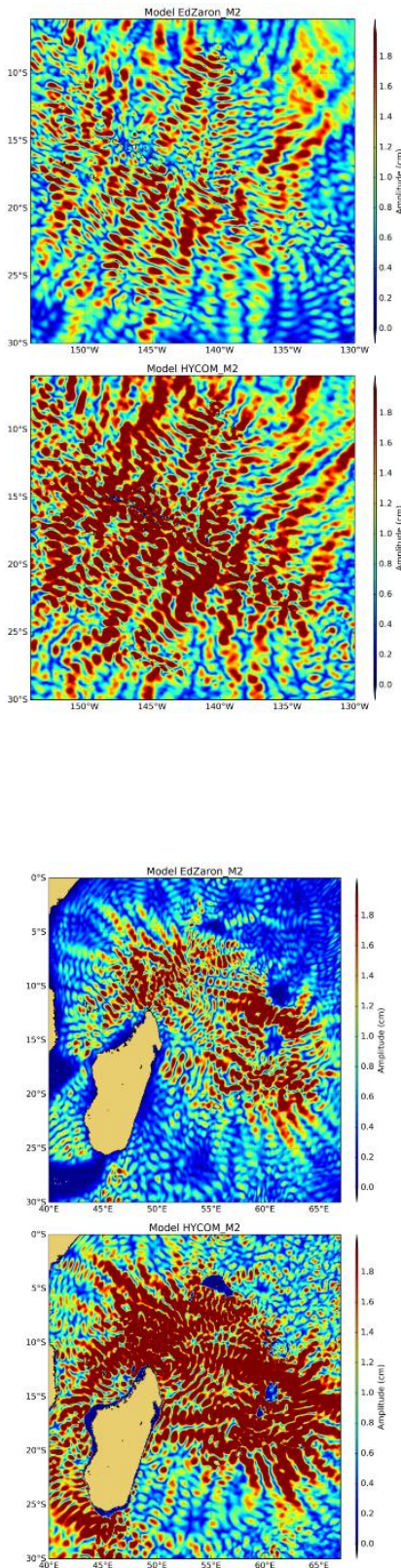